artelogie

\section{Artelogie}

Recherche sur les arts, le patrimoine et la littérature de l'Amérique latine

$10 \mid 2017$

Après le paysage : l'art, l'inscription et la représentation de la nature en Amérique latine aujourd'hui

\title{
Picasso y los artistas del continente latinoamericano
}

Jacques Leenhardt

\section{(2) OpenEdition \\ Journals}

Edición electrónica

URL: http://journals.openedition.org/artelogie/950

DOI: $10.4000 /$ artelogie. 950

ISSN: 2115-6395

Editor

Association ESCAL

Referencia electrónica

Jacques Leenhardt, " Picasso y los artistas del continente latinoamericano », Artelogie [En línea],

10 | 2017, Publicado el 05 abril 2017, consultado el 19 abril 2019. URL : http://

journals.openedition.org/artelogie/950; DOI : 10.4000/artelogie.950

Este documento fue generado automáticamente el 19 abril 2019.

Association ESCAL 


\title{
Picasso y los artistas del continente latinoamericano
}

\author{
Jacques Leenhardt
}

\section{Preámbulo}

1 Actualmente, los historiadores latinoamericanos han comenzado una reescritura de su propia historia del arte, ya sea a través de una revaluación de la manera como fue vivida y en parte superada- la dependencia cultural del continente con respecto a Europa y a los Estados Unidos o bien a través de la reevaluación de las herencias ligadas a las culturas autóctonas y africanas.

2 En efecto, la historia del arte mantuvo durante largo tiempo un pensamiento de tipo difusionista, que dio principalmente a Europa el rol de centro de producción de bienes simbólicos y concede al resto del mundo, percibido como una simple periferia, sólo un rol subalterno de imitador servil. Sin embargo, si el flujo de intercambios fue constante, y a veces en los dos sentidos, ${ }^{1}$ la noción de influencia no es suficiente para caracterizar estos intercambios. Hay que saber interpretar lo que fueron a menudo de la parte de los artistas latinoamericanos unas verdaderas apropiaciones, una masticación antropofágica como decía Oswald de Andrade ${ }^{2}$. La cultura de los centros hegemónicos se encontró digerida y así transformada y resimbolizada en función de las culturas locales que acababa de enriquecer y de las transformaciones en las que participaba.

\section{Las Américas Latinas y Picasso}

«Todos, incluido yo, nacimos de un dedo de Picasso.» declaró el pintor venezolano Oswaldo Vigas, antes de continuar que, en su caso, esa influencia fue particularmente reducida. En este balanceo entre influencia y autonomía aparece una situación compleja. Todas las obras críticas están de acuerdo sobre este tema: la obra de Picasso marcó, de una manera o de otra, a una gran parte de los pintores de su siglo. Una influencia debida a 
la bulimia experimental del mismo Picasso, que nunca cesó de confrontarse con la pintura y su historia. Como dice Marie-Laure Bernardac, Picasso es «un fénix que renace eternalmente de sus cenizas, utilizando su energía creativa en un proceso de desconstrucción-reconstrucción del Padre, de muerte y resurrección.» ${ }^{3}$ En realidad, Picasso deja afuera de su campo de actividad esa ofensa infligida a la tradición pictórica que fue la cuestión «conceptual» desarrollada por Marcel Duchamp. También queda afuera la abstracción propiamente dicha, que tendrá una gran importancia en América Latina bajo el nombre de arte concreto, abstracción geométrica o de op'art.

De todos estos numerosos y diversos intercambios, yo retendría tres situaciones en las cuáles Picasso constituye, según mi opinión una referencia pertinente.

\section{El período cubista, como imaginación de una nueva estructura de la representación}

Desde los finales del siglo XIX, un gran número de países del continente fueron sacudidos no sólo por grandes cambios políticos, sino también económicos y sociales que nutren un contexto muy poderoso de reivindicaciones: abolición de la esclavitud y declaración tardía de la República en Brasil en 1888 y 1889, inmigración masiva de 55 millones de europeos entre 1820 y 1920, invasión de capital extranjero, desarrollo de las comunicaciones, expansión urbana, movimientos sociales y reivindicación de revueltas de épocas pasadas.

Estos breves repasos históricos dibujan el contexto de la experiencia íntima de los artistas latinoamericanos en búsqueda de una expresión que, en su forma, fuese moderna, a la altura de las transformaciones que se estaban viviendo. Para ellos, lo que el cubismo elaboraba en París no era, en efecto, realmente un estilo pictórico, y tampoco una receta para producir cuadros "modernos" para los cuales de todas maneras no había un mercado en sus países. Se trataba más bien de poner en práctica una ruptura radical en el continuum del ambiente académico y elaborar, apoyándose en las revoluciones estéticas europeas, un lenguaje susceptible de presentar el nuevo curso de la realidad latinoamericana. Estos artistas inquietos, que pertenecían casi todos a las clases superiores de su sociedad, buscaban a través de esos diversos experimentos, transmitir por medio de su arte las transformaciones de las cuales ellos eran testigos en sus propios países. Es justamente eso que les fascinaba en el experimentalismo, del que Picasso era la figura emblemática. Sin duda, dichas soluciones no estaban acordes con su medio, siendo producto de un proceso que ya había superado la modernización de la Europa industrial. El continente latinoamericano estaba sólo en los albores de estos tiempos nuevos, pero pronto iba a «digerir» $\mathrm{y}$ «transformar » sobre su propio suelo y en su propia piel esas innovaciones artísticas que descubrían y pedían prestado a París.

7 Durante largos decenios, esta generación estaría en un constante ir y venir, entre sus propias tradiciones locales y la modernidad formal que venía de Europa. Es evidente, que la adhesión atávica hacia una tierra que continuaba dictando sus leyes, sólo podía entrar en contradicción con el deseo cosmopolita de emanciparse de una realidad, cada vez más agresivamente marginalizada por la evolución del mundo moderno. ${ }^{4}$

En referencia a este tema, es interesante constatar que la influencia de un artista como el uruguayo Pedro Figari (1861-1938), muy alejado de las preocupaciones formales de la composición-descomposición cubista, no dejará nunca de hacerse sentir incluso en 
pintores embebidos de modernidad. Así, su compatriota Rafael Pérez Barradas (1890-1929) tiene una relación menor con el cubismo de un Braque o de un Picasso que a través de la versión futurista desarrollada por el italiano de París Gino Severini. Las vistas animadas del metro o de la calle parisina, creadas por este artista, seducían más a un pintor habituado a las escenas de índole tradicional en la pintura del Río de la Plata, y en la obra de Figari en particular.

También el argentino Emilio Pettorutti (1892-1970) permaneció sin duda fiel al cubismo a lo largo de toda su carrera, pero es en Italia, junto con el brasilero Ismaël Nery (1900-1934), que se encuentra con las formas cubo-futuristas que le interesarán primero, para luego ceder a la influencia de Juan Gris y Albert Gleize. En fin, si la referencia a Picasso es evidente en El Quinteto, (1927), el estilo de Pettorutti evolucionará hacia una abstracción fuertemente geométrica que lo alejará definitivamente de la primera influencia cubista: (Quietud más allá, 1956-57).

10 Encontramos los mismos elementos de diversidad en las peregrinaciones del uruguayo Joaquín Torres-García (1873-1949). Tras trabajar en Barcelona con Gaudí, Torres-García se dirige hacia el arte mural; luego pasa un tiempo en Italia, después en Nueva York y posteriormente en París donde encontrará a Picasso. Su Album de Nueva York (1920) lleva la marca de este diálogo. Pero, es sobre todo con los iniciadores del neo-plasticismo: Theo van Doesburg, Michel Seuphor, Piet Mondrian y Jean Hélion, en cuya complicidad concebirá lo que será finalmente su propio lenguaje, que el inventor del constructivismo universalista creará escuela en los años cuarenta en particular en Montevideo.

Esta biografía discontinua es muy típica del recorrido de los artistas e intelectuales latinoamericanos. En éste, París funciona como el epicentro de la modernidad, Múnich como el centro del expresionismo e Italia como el lazo umbilical con la tradición. En esta historia, Picasso es el nombre emblemático de un movimiento que revoluciona la representación pictórica del mundo, pero que reposa en varios artistas y en una diversidad de tendencias en el interior de esta corriente: Léger, Gleize, Metzinger o Marcoussis.

La emigración más tardía de artistas como Lasar Segall (1891-1957) en Brasil testifica de la mezcla de influencias comparables, donde el expresionismo tiene un papel importante. Un pintor como el chileno Manuel Ortiz Zarate (1887-1946), permanecerá más ligado a los cafés de Montparnasse (Apollinaire habla de él como del «único Patagón de París»), desarrollando una obra profundamente inscrita en el estilo cubista, a tal punto que establecerá un contrato con el gran marchand de Picasso y del grupo: Léonce Rosenberg. Es el caso también del mejicano Diego Rivera, quien proclamó con toda franqueza: «nunca creí en Dios, pero creo en Picasso», y que, en su autobiografía subraya: «Casi ningún pintor posterior ha escapado a su influencia... Durante mis iniciales días en París, primero fui discípulo de Picasso y más un tarde su amigo". ${ }^{5}$ Sin embargo, lo que distingue a Diego Rivera, en su apego hacia la persona de Picasso, es que puede servir de figura de transición entre el periodo cubista y los años veinte donde dominará el segundo tema que quisiera abordar : el arte mural y la política.

\section{El arte y lo político}

Desde la caída del dictador Porfirio Díaz, en el poder sin discontinuidad desde 1876, y desde el inicio de la «revolución» y la guerra civil mejicana que terminaría en 1920 con la toma de poder del General Obregón, un cambio profundo se produjo en el paisaje artístico 
mejicano. Bajo la dirección del Sindicato de pintores, escultores y grabadores revolucionarios se expresa la necesidad de hacer del arte el portavoz de la realidad social y política. Diego Rivera (1886-1957) es incontestablemente el principal motor de este movimiento, en el cual se mezclan elementos propiamente estéticos y consignas políticas, con el objetivo de dar a un pueblo ampliamente iletrado, imágenes susceptibles de movilizarlo y así fomentar la construcción de una consciencia social y política nacional. Cuando Rivera decide salir del marco limitado del cuadro de caballete, redescubre toda una parte de la historia de la pintura cuyas referencias van desde la obra de Giotto y del Renacimiento italiano hasta el que fue el último continuador: Puvis de Chavannes (1824-1898). Dichas preocupaciones, a las cuales la revolución soviética daba actualidad, tenía como objetivo resaltar la función social del arte en una sociedad que se encontraba en plena transformación. Diego Rivera formuló claramente estas exigencias nuevas. Desde la guerra, Rivera se alejó del cubismo y de Picasso, pensando que los refinamientos del cubismo analítico no estaban a la medida de un tiempo donde las masas iban a convertirse en el actor social y por lo tanto cultural dominante.

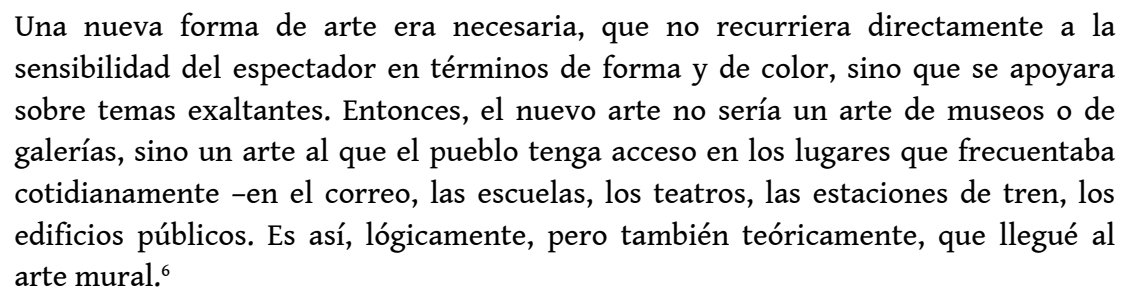

14 Las exigencias de la actualidad que movilizan a los artistas mejicanos se encuentran en otros países del continente bajo formas a menudo muy parecidas. En Argentina Antonio Berni (1905-1981), después de un período en el que su pintura se acerca al movimiento surrealista, proclama que a partir de ahora ningún artista latinoamericano puede exonerarse de tener en cuenta el sufrimiento del pueblo. Durante la dictadura Berni se orienta hacia una figuración de carácter social poniendo en escena las luchas sociales y el desempleo (La manifestación, 1934).

15 A diferencia de Rivera, Berni no le debe nada directamente a Picasso, como tampoco la otra artista argentina: Raquel Forner (1902-1988) que se había nutrido en París de la enseñanza de Othon Friez a finales de los años veinte. Pero estos artistas y decenas de otros como ellos -en Buenos Aires alrededor del Grupo Florida, en Brasil, en Méjico y en otras partes de América Latina- constituyeron un ambiente rico y diverso que considera su trabajo como un compromiso político o más ampliamente humanista. Sin embargo, después del Guernica (1937) y de su adhesión al partido comunista, Picasso se convertirá en la referencia obligada de este movimiento de arte comprometido, que no influenció al principio, pero que luego va a utilizarlo como testigo de un mundo de sufrimiento.

16 A este respecto, el caso más interesante es tal vez el de Cándido Portinari (1903-1962). Contrariamente a muchos artistas de esta época, Portinari proviene de un ambiente pobre y rural. La experiencia de los problemas de la vida rural, de la misma manera que había influenciado a Jean-François Millet en el siglo XIX, le otorga al pintor brasilero una mirada atenta a las penas de una población sometida a los peligros de la lluvia y la sequía en el sertão, de donde éste era originario. Portinari expone en su pintura un arte social y políticamente comprometido que no disimula el sufrimiento bajo la máscara de la belleza. Su cuadro Os Retirantes (1944), expuesto en París en 1946, lleva al extremo esta visión cruda de la miseria, a tal punto que el patetismo de algunas de sus telas será a menudo criticado como manifestando cierto "miserabilismo", o incluso «dolorismo». Portinari 
desarrollará igualmente un arte mural más apaciguado, que ilustra la epopeya del café en un estilo que reanuda con el espíritu de Diego Rivera.

No obstante, desde esa época y hasta los años 1950, la cuestión del compromiso social del arte sigue ampliamente vigente en todo el continente, y con la siguiente consecuencia que subraya Francisco Alambert: «El arte moderno debía crear, recrear y educar al público para un país nuevo, un nuevo mundo y un nuevo futuro. Para ello, en Brasil, más que en cualquier otro lado, el arte debía comunicar». ${ }^{7}$ El terreno había sido preparado para reorientar la práctica artística hacia lo social y lo político, al mismo tiempo que una recepción particularmente atenta del Guernica. Las situaciones son sin embargo diversas. En los frescos del Palacio Municipal de Méjico, Diego Rivera había cantado la epopeya revolucionaria del progreso. La Historia con mayúscula se manifestaba mediante los frescos ante los ojos maravillados de un pueblo que quería participar. Después, en una dirección expresionista violenta, David Alfaro Siqueiros (1896-1974) y José Clemente Orozco (1883-1949) agregaron a esta epopeya optimista su lado sombrío y trágico.

Picasso traerá, con Guernica un cambio fundamental, pero siempre manteniéndose dentro de una pintura de testimonio. Consigue a través de esta pintura, arrancar a la figuración mucho más que un mensaje, mucho más que una simple representación de actos de violencia. Apoyándose en la descomposición del espacio que había conseguido en la época cubista, sobrepasa todo mensaje identificable para producir una imagen absoluta del dolor.

En esta experiencia del choque extremo que le produjo la destrucción de tantas vidas y de la esperanza republicana en España y frente a la manifestación hiperbólica de la brutalidad sanguinaria, Picasso sitúa la imagen muy cerca del dolor más concreto. El bombardeo de Guernica, incluso antes de los horrores de la Segunda Guerra Mundial, se convierte en la manifestación de la capacidad humana de autodestruirse. Esta revelación es como el revés del optimismo de Rivera. En Guernica, la pintura se aleja de toda anécdota para mostrar solamente, en un caleidoscopio de imágenes fragmentarias, la expresión de desesperanza absoluta del pintor delante de la manifestación de violencia. Picasso desvela ante nuestros ojos, en el mismo momento en que pinta el lienzo, el abismo de dolor que se abre delante de él.

Hubo en esta época un debate importante para saber si era el caballo herido o el toro que representaba al pueblo español. Alfred Barr, director del MoMA de Nueva York donde la obra fue finalmente expuesta, organizó un coloquio sobre el tema. ${ }^{8}$ Se trataba de resolver la cuestión de la simbología iconográfica del cuadro. Pero en realidad, Picasso había radicalmente superado el nivel de lectura requerido por un arte «comprometido» o partisano. El Guernica estaba de hecho situado en un plano que supera la figuración, por lo que ya no permitía entonces identificar a los buenos, las víctimas y los verdugos. Guernica es el momento incandescente donde el arte y la vida, en su diferencia absoluta (la cual todo el siglo del modernismo ha tratado de superar) se encuentran de $\eta$ Masacres de Corea (1951) en un plano descriptivo. No volverá a encontrar los recursos estéticos y morales que le habían permitido disolver el arte y la emoción vital en una obra única. Con Los Masacres de Corea, Picasso vuelve una vez más sobre la cuestión de la violencia política, a la confrontación con la historia de la pintura, con Goya y Manet, dos de sus interlocutores privilegiados junto a Velásquez.

21 La fuerza del ejemplo Guernica por lo tanto no estaba extinta. Wifredo Lam (1902-1982) había venido de Cuba a Europa, y había estado presente en la guerra de España en 1937. 
Muy ligado a Picasso desde su llegada a París en 1938, Lam pintaba por aquel entonces figuras humanas en un estilo muy influenciado por el cubismo pero también muy cercano a Matisse. Luego, súbitamente en el invierno de 1940, cuando espera un barco en Marsella para un nuevo exilio, Lam dibuja para el poema Fata Morgana de Breton, unas figuras que no parecen venir de ningún lado. No se trata ni de hombres ni de mujeres, ni de monstruos. ¿Se trata quizás de figuras de dioses? ¿Acaso el cubismo no había descubierto en las máscaras de los cultos animistas africanos soluciones plásticas inéditas? ¿Tal vez la experiencia del vudú había alimentado esa manera de pintar el terror sobre el lienzo?

Lo cierto es que es Wifredo Lam quien intentará la imposible empresa, emblematizada por Guernica, de representar la tragedia de la humanidad sin pasar por la figuración «realista». Lam no será ni verdaderamente surrealista, ni evidentemente abstracto, pero explorará esa zona crepuscular, entre dos luces, donde todo puede decirse acerca de los dramas humanos, sin que nada pueda ser reconocido. En esta obra secreta, que se desarrollará a lo largo de los años cuarenta y cincuenta, resurge algo del éxito misterioso de Guernica y es, sin duda, por eso que Picasso tendrá gran estima y amistad por Lam.

No hay duda que la exposición de Guernica, en 1953, en el marco de la segunda Bienal de São Paulo marcó una vez más todos los espíritus. La violencia que Rufino Tamayo (1899-1991) había tratado de expresar en sus lienzos «comprometidos» de los años cuarenta, que volvemos a encontrar en el colombiano Alejandro Obregón (1920-1992) y el ecuatoriano Oswaldo Guyasamín (1919-1999), intentará de darle a su vez una expresión que nos remite la iconografía de Guernica.

Sin embargo, la presentación única en América Latina de esta pintura emblemática, que se asocia tan bien a los debates estéticos de la guerra fría, interviene ampliamente a contratiempo en un Brasil donde la cuestión política se alejó bajo la presidencia de Juscelino Kubitschek. En arte, la abstracción domina ahora a una generación movilizada por la dinámica de una modernización industrial acelerada.

\section{Ironía, grotesco y carnaval}

25 El tercer encuentro entre Picasso y los artistas latinoamericanos se inscribe claramente en el seno de la figuración. Se apoya en un espacio difractado y multidimensional abierto por el cubismo y, en un plano más antropológico, desarrolla una dramaturgia donde la deformación toma todo su lugar en tanto que inflige tortura a la figura humana. En Picasso siempre hay, más allá de la alegría vital que baña una gran parte de su obra, una dimensión trágica que encuentra en la distorsión infligida a la figura humana una dimensión irónica, carnavalesca, que viene de Goya y nos conduce a Bacon. Esta ironía posee por lo menos dos fuentes íntimas en Picasso: la de la tragedia humana de la que fue cuestión y la de la confrontación con las obras canónicas de la historia del arte.

En el planteamiento que hace de sus maestros, Picasso produce a la vez un homenaje y una desacralización. La ironía de múltiples «recuperaciones » de Las Meninas de Velásquez como en las deformaciones infligidas a las figuras de Ingres o Delacroix, testimonia principalmente de una libertad irreverente. La galería de arte que la tradición ofrece como modelo se convierte súbitamente en un carnaval grotesco, y los «inspirados de» a menudo no son más que una palinodia salvaje. Picasso, desde este punto de vista; es el más grande antropófago de la historia del arte. 

este carnaval de vanidades pintado, constituirá un acto poderoso de liberación, un ejemplo liberador para la pintura figurativa latinoamericana. Y tanto más que las circunstancias políticas del continente, en los años 1960-1970, constituidas de dictaduras y de poderes ilegítimos, alimentan la rabia de los artistas contra sus propios gobernantes. Tomar en serio la representación, no sería la cuestión, en un momento en que se difunde la violencia abyecta de los poderes. Un artista como Jacobo Borgès sintió esta fuerza de la ironía en la pintura.

Alimentado por los horrores del franquismo (Songe et mensonge de Franco, 1937), este aspecto carnavalesco de la pintura de Picasso se encuentra así, en América Latina, con la experiencia de pueblos sometidos ampliamente al imperialismo americano y a sus fantoches.

Pero también está el aspecto formal de esta mortificación infligida a la figuración. Esta se convierte en dé-formación, distancia tomada hacia la forma, principalmente humana. Irrisión y figuración carnavalesca son entonces las modalidades expresivas de una desconfianza hacia las imágenes serenas, presentadas como desmitificaciones ofrecidas a la credulidad de los pueblos. Recuperación desplazada, ironía mordaz, blasfemia, tales son los registros en los cuales la vena picassiana tuvo larga posteridad inesperada, donde se funde con el espíritu desconfiado hacia toda realidad que se nombra o nombramos « realismo maravilloso ». Picasso no es solamente en ese momento el maestro de formas que había sido en el periodo cubista, luego en los años veinte e incluso en Guernica. El viejo pintor se convirtió para esta nueva generación en un gran destrozador sin vergüenza que copia, tritura y transforma las imágenes. Un poco en todos lados, y particularmente en Brasil donde había dominado la abstracción neo-concretista, se ve renacer la figuración con la vuelta de la dictadura: «una especie de arte comprometido emerge con los nuevos artistas cuya crítica tiene como objetivo no solamente la masificación social, local y mundial, sino también el autoritarismo local. »9

Lo más interesante, en efecto es que son los nuevos medios artísticos, pop, happening, carnavalización de las imágenes que irrigan ahora la producción contestataria de un Rubens Guerchman (1942-2008) en Brasil. Se trata de hacer explotar al gran día la brecha abisal y trágica entre los valores que proclaman estas sociedades autoritarias y las realidades que ofrecen a sus ciudadanos. En este asunto, la carnavalización de las imágenes que multiplica la sociedad de consumo y las del arte legítimo, se mezclan colgadas en las cornisas de los museos.

Una venganza Dada, una falta de respeto libertario, sobre el cual vela la figura guasona de Picasso, impregna una gran parte del arte producido en estos años en América Latina. Lo que el padre tutelar de la pintura del siglo XIX deja a esta generación de los años ochenta es la libertad y el eclecticismo, la realidad visitada por los sueños, en resumen una nueva manera de abordar la pintura. No hay que olvidar, en efecto, que Picasso ha sido el primero en asumir, con todo su oficio, lo efímero y lo aproximado de la pintura, esa burla a la tradición que enseñará una vez más a aquellos que le miren, a respetar y a olvidar. 


\section{NOTAS}

1. Pierre Kalfon y Jacques Leenhardt, Les Amériques latines en France, Paris, Gallimard, 1992

2. Diferentes nociones fueron avanzadas para caracterizar la singularidad de la recepción de los productos culturales de los centros : " la antropofagia » de Oswald de Andrade (manifesto antrópophago, Brasil, 1982), la « transculturación » de Fernando Ortiz (contrapunteo cubano del tabaco y azúcar, Cuba, 1940) el " mestizaje » en sus diferentes mecanismos (Gilberto Freyre, Edouard Glissant)

3. Marie-Laure Bernadac, «Picasso cannibale, destruction-reconstruction des maîtres ", in Picasso et les maîtres, catalogue de l'exposition éponyme, Réunion des Musées Nationaux, 2008, p.49

4. Ver: Beatriz Sarlo, Una modernidad periférica: Buenos Aires, 1920 y 1930. Buenos Aires, Ediciones Nueva Visión, 1988

5. Azuela Alicia. 1985. Diego Rivera en Detroit. México: Universidad Nacional Autónoma de México, p. 143

6. Diego Rivera, My art, my life: an autobiography (with Gladys March) nuestra traducción orginal del texto está disponible en: https://books.google.fr/books?

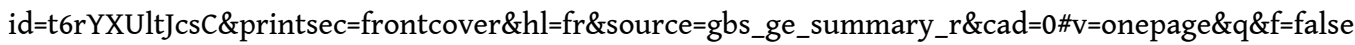
7. Francisco Alambert : "El Goya vengador en el Tercer Mundo : Picasso y Guernica en Brasil", in El Guernica de Picasso : el poder de la representación, Europa, Estados Unidos y América Latina, Buenos Aires, Editorial Biblos, 2009 pp. 69-70 (nuestra traducción)

8. Referirse sobre este tema al artículo muy detallado de Andrea Giunta «El poder de la interpretación (como Alfred Barr explicó el Guernica al público del MoMA) », in Artelogie [En ligne], 10|2017, mis en ligne le 11 mai 2017, consulté le 18 mai 2017. URL: http:// artelogie.revues.org/953

9. Franciso Alambert: «El Goya vengador en el tercer mundo: Picasso y Guernica en Brasil », op. cit. p. 75 (nuestra traducción)

\section{AUTOR}

JACQUES LEENHARDT

EHESS 